\title{
Mutação missense de novo patogênica c.2415C G (p.Asp805Glu) no gene ATP1A3 em paciente com hemiplegia alternante da infância com resposta favorável ao cloridrato de biperideno
}

Gabriela Cabrera Garbuio ${ }^{1}$ (D), Jéssica Rezende Mio $^{1}$ (D), Letícia Cassaro Feltrin ${ }^{1}$ (으, Marina Soccal da Silva $^{1}$, Zumira Aparecida Carneiro ${ }^{(\mathbb{D}}$, Charles Marques Lourenço ${ }^{1}$

\begin{abstract}
RESUMO
A Hemiplegia Alternante da Infância é um distúrbio neurológico grave e uma doença rara (1 em cada 100.000 recémnascidos), caracterizado por ataques repetidos transitórios de hemiplegia episódica ou tetraplegia que podem durar minutos a horas, acompanhados por outros sintomas paroxísticos como anormalidades oculomotoras e autonômicas, distúrbios do movimento como ataxia, comprometimento cognitivo progressivo, convulsões, distonia e coreia. Os tratamentos atuais são amplamente sintomáticos. Neste relato de caso, apresentamos paciente do sexo feminino, 18 anos, na qual aos 10 meses apresentou o primeiro episódio aparente de crise convulsiva com versão ocular. 0 eletroencefalograma e tomografia computadorizada não revelaram anormalidades e foram administradas diversas medicações como fenobarbital, carbamazepina, valproato de sódio, topiramato, dicloridrato de flunarizina, clonazepam, cipro-heptadina e pizotifeno, todos sem resultado. Devidos aos sintomas extrapiramidais, paciente passou a utilizar biperideno, apresentando não só melhora da distonia, mas também no número de crises hemiplégicas. Aos 13 anos, ela foi diagnosticada com Hemiplegia Alternante da Infância na mutação patogênica missense de novo c.2415C G (p.Asp805Glu) no gene ATP1A3 apresentando boa resposta ao tratamento com cloridrato de biperideno.
\end{abstract}

Palavras-chave: Hemiplegia, Disfunção cognitiva, Convulsões, Biperideno.

1. Faculdade de Medicina - Centro Universitário Estácio de Ribeirão Preto, Ribeirão Preto (SP), Brasil. 


\section{INTRODUÇÃO}

A Hemiplegia Alternante da Infância (Alternating Hemiplegia of Childhood - AHC) é uma grave e rara doença neurológica geneticamente determinada, acometendo cerca de 1 em cada 100.000 recém-nascidos, decorrente de mutações heterozigóticas de novo de ATP1A3 ${ }^{1-3}$.

O gene ATP1A3 pertence a uma família de genes que são responsáveis por codificar as subunidades alfa 3 da proteína ATPase transportadora de sódio - potássio $(\mathrm{Na}+/ \mathrm{K}+)$ cuja função é regular, por transporte ativo, os gradientes de concentração de sódio e potássio, íons essenciais para o controle da osmolaridade celular e dos potenciais de ação da membrana excitável ${ }^{1,4}$. ATP1A1, ATP1A2 e ATP1A3 codificam as subunidades alfa 1, 2 e 3, respectivamente, expressas principalmente em interneurônios e células piramidais, sugerindo que elas desempenham papéis importantes no cérebro, embora ainda não se compreenda completamente como mutações no gene ATP1A3 levam ao fenótipo clínico das crises hemiplégicas recorrentes ${ }^{4}$.

Mutações no gene ATP1A3 estão associadas a, pelo menos, três síndromes neurológicas distintas, porém sobrepostas: a síndrome do parkinsonismodistonia de início rápido; a síndrome da hemiplegia alternante da infância; e síndrome CAPOS (Cerebelar, Ataxia, arreflexia, Pes cavus, Optic atrophy Sensorineural hearing loss) $)^{5,6}$.

A AHC se caracteriza por ataques repetidos transitórios de hemiplegia episódica ou tetraplegia que podem durar minutos a horas, acompanhada por outros sintomas paroxísticos, como anormalidades oculomotoras e autonômicas, distúrbios do movimento como ataxia, comprometimento cognitivo progressivo, convulsões, distonia e coreia. Geralmente, a AHC se apresenta na infância, com início das manifestações e dos sinais e sintomas geralmente antes dos 18 meses $^{1,4}$.

AHC é observada predominantemente em casos esporádicos sem história familiar, embora também tenha sido relatado AHC familiar com herança autossômica dominante ${ }^{4}$.

Os tratamentos atuais são amplamente sintomáticos e incluem agentes que induzem o sono, como benzodiazepínicos ou hidrato de cloral, para interromper episódios prolongados de hemiplegia ou distonia?.
Aproximadamente $50 \%$ das crianças com AHC também têm diagnóstico de epilepsia, embora a certeza desse diagnóstico possa permanecer indefinida devido à semelhança na apresentação clínica entre eventos epilépticos e não epilépticos paroxísticos, como distonia, tremor ou paresia ${ }^{8}$.

\section{RELATO DE CASO}

Paciente, sexo feminino, 19 anos, filha de pais jovens e não consanguíneos, e sem histórico familiar de doença neurológica, foi encaminhada para avaliação de "crises convulsivas de difícil controle".

Paciente nasceu a termo (38 semanas e 5 dias), parto normal, comprimento de $47 \mathrm{~cm}$, pesando $3.180 \mathrm{~g}$, perímetro cefálico $(P C) 35 \mathrm{~cm}$, gestação sem intercorrências clínicas. Apresentou Apgar 8 e 9 (primeiro e quinto minutos respectivamente). Andou aos 2 anos e 2 meses, sentou com 1 ano e meio e iniciou a fala com 3 anos. Não apresentou outros problemas de saúde até os 10 meses quando apresentou o primeiro episódio aparente de crise convulsiva com versão ocular, requerendo avaliação com o neurologista.

Foram solicitados eletroencefalograma e tomografia computadorizada, os quais não revelaram anormalidades. A paciente foi diagnosticada com crises convulsivas focais tipo versivas e iniciou uso de fenobarbital até sua dose máxima de $4 \mathrm{mg} / \mathrm{kg} / \mathrm{dia}$.

Com 1 ano e 10 meses a paciente apresentou hemiplegia ambos os membros superiores com duração de 5 a 30 minutos, em alguns momentos com duração de horas e com uma frequência de 2 a 3 crises por semana. Genitora relata que, até então, esse fato nunca tinha ocorrido. Refere também que algumas vezes, em conjunto com a perda de movimento, a paciente apresentava olhar fixo e perda da fala.

Após dois meses do episódio anterior, a paciente foi encaminhada pelos pais a unidade de emergência, por apresentar crises convulsivas durante dois dias consecutivos. O valproato de sódio foi administrado na sua dose máxima de 60 $\mathrm{mg} / \mathrm{kg} /$ dia e foi substituído por carbamazepina gradativamente. Com o uso da carbamazepina na dose máxima de $1200 \mathrm{mg} /$ dia, porém, a paciente continuou com hemiplegia, agora apenas do membro superior direito e perda da fala mantendo a duração 
de 5 a 30 minutos em alguns momentos com duração de horas e a frequência de 2 a 3 crises por semana.

Aos 2 anos e 8 meses a paciente permanecia com hemiplegia dos membros superiores e perda da fala com uma frequência variável, mantendo-se, em geral, entre 2 a 3 crises por semana.

Aos 6 anos a paciente fez uso das seguintes medicações: fenobarbital, pizotifeno, dicloridrato de flunarizina todos em dose máxima e foi adicionado lamotrigina ( $500 \mathrm{mg} / \mathrm{dia}$ ). Após 3 meses, foi retirado pizotifeno. Não houve melhoria dos episódios de hemiplegia nem das crises de alteração ocular. Exame realizado de ressonância magnética de encéfalo foi compatível com a normalidade.

Aos 10 anos a paciente apresentou episódio de crise convulsiva mais significativa e foi adicionado clonazepam $20 \mathrm{mg} /$ dia em conjunto com o topiramato (1600 mg/dia). Paciente, evoluiu, contudo, aos 11 anos, com regressão da fala, com genitora referindo episódios esporádicos de disfagia e em uso de cadeira de locomoção devido à instabilidade de deambulação, desequilíbrio e quedas frentes.

Dos 10 meses aos 13 anos, a paciente usou vários esquemas terapêuticos, como carbamazepina $1.200 \mathrm{mg} / \mathrm{dia}$, valproato de sódio $60 \mathrm{mg} / \mathrm{kg} / \mathrm{dia}$, dicloridrato de flunarizina, $10 \mathrm{mg} / \mathrm{dia}$, topiramato $1600 \mathrm{mg} /$ dia, cipro-heptadina $16 \mathrm{mg} /$ dia, pizotifeno $1,5 \mathrm{mg} / \mathrm{dia}$, lamotrigina $500 \mathrm{mg} / \mathrm{dia}$ e clonazepam $20 \mathrm{mg} /$ dia.

Aos 13 anos, após avaliação com geneticista, solicitou-se sequenciamento do gene ATP1A3, com presença de mutação missense de novo patogênica c. $2415 \mathrm{C}>\mathrm{G}$ (p.Asp805Glu) no éxon 17, confirmando o diagnóstico de hemiplegia alternante da infância. Essa mutação já havia sido previamente descrita na literatura em outros pacientes com essa enfermidade.

Atualmente, a paciente faz uso de clonazepam, risperidona e cloridrato de biperideno (introduzido inicialmente para tratar síndrome distônica da paciente). Depois da introdução do último medicamento, não apresentou mais crises, revelando uma melhora na qualidade de vida e uma lentificação na evolução da doença. Acerca de seu desenvolvimento neuropsicomotor, não sabe ler e nem escrever, fala com dificuldade, apresenta compreensão, deambula independentemente, realiza as atividades diárias, frequenta escola regular em sala especial e realiza múltiplas terapias de reabilitação, como fonoaudiologia, psicopedagogia e fisioterapia.
Ao exame físico atual, paciente apresenta fácies simétrica, hipomímica, sem alterações da movimentação ocular, força muscular preservada em membros superiores e inferiores, reflexos vivos globalmente, tônus diminuído em membros inferiores, dismetria, disdiadococinesia, distonia em mãos, sensibilidade preservada e marcha com base discretamente alargada.

\section{DISCUSSÃO}

A AHC é uma enfermidade genética causada, na maior parte das vezes por mutações no gene ATP1A3 (responsável por $74 \%$ dos casos de AHC) ${ }^{9}$. Vale salientar que a AHC é uma entidade heterogênea do ponto de vista genético, pois mutações em outros genes já foram identificadas como responsáveis por esse quadro clínico. Entre eles, mutações nos genes CACNA1A, SLC2A1, SLC1A3 e ATP1A2 foram identificadas em uma pequena parcela de pacientes com AHC, mas geralmente esses pacientes apresentam os episódios de hemiplegia associados a um quadro clínico mais atípico. De forma geral, na maior parte dos artigos publicados, o gene ATP1A3 é o responsável majoritário pelos casos de $\mathrm{AHC}^{9}$.

No caso do gene ATP1A3, trata-se de um gene cuja função é codificar as subunidades (isoforma) alfa 3 da proteína ATPase transportadora de sódio - potássio $(\mathrm{Na}+/ \mathrm{K}+)$, responsável pelo estabelecimento e manutenção de gradientes eletroquímicos de íons sódio e potássio através da membrana plasmática dos neurônios (Figura 1), íons essenciais para o controle da osmolaridade celular e dos potenciais de ação da membrana excitável ${ }^{10}$.

Além da AHC, foram relatadas outras doenças associadas a mutações heterozigotas do gene ATP1A3, como a síndrome do parkinsonismodistonia de início rápido (RDP) e a síndrome CAPOS (ataxia cerebelar, arreflexia, pé cavo, atrofia óptica e perda auditiva neurossensorial) ${ }^{9}$. São doenças clinicamente diferentes da AHC, mas que possuem alguns elementos em comum como os sintomas extrapiramidais (ataxia cerebelar, distonia), o que revela a ampla variedade de expressão fenotípica de mutações nesse gene.

Os primeiros sintomas da AHC ocorrem antes dos 18 meses como o observado com nossa paciente cujos sintomas surgiram em torno dos 10 meses. Caracterizam-se por hemiplegia com duração 


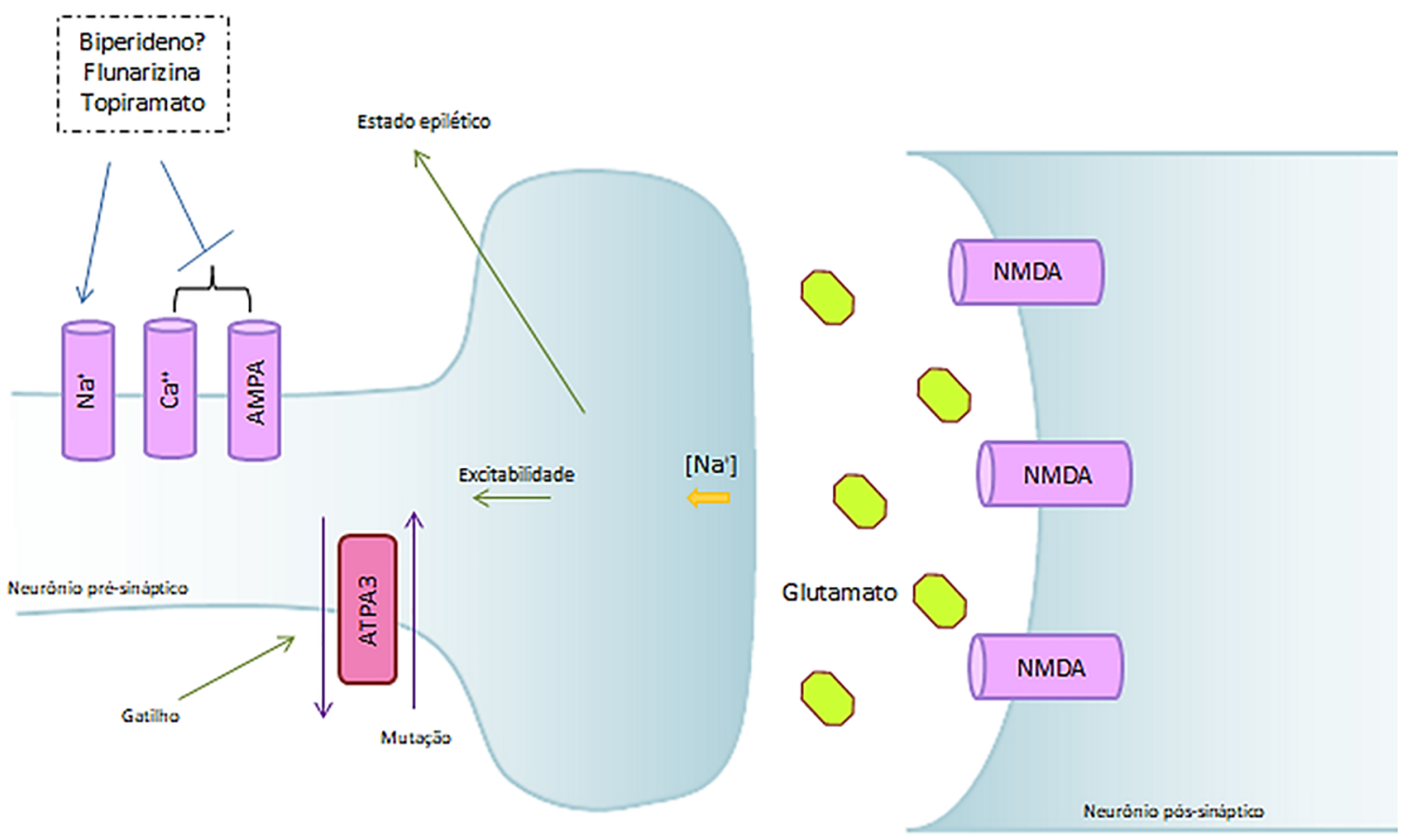

Figura 1: Adaptado de Algahtani H. et. Al. Representação esquemática mostrando atividade disfuncional da bomba de Na + /K + -ATPase devido à mutação de ATP1A3 em neurônios que afetam a atividade do sistema glutamatérgico. A mutação no ATP1A3 provoca uma diminuição na atividade da bomba de $\mathrm{Na}+/ \mathrm{K}+$-ATPase e um aumento do $\mathrm{Na}+$ intracelular, que resulta em hiperexcitabilidade que afeta a função neuronal. A flunarizina e o topiramato são mostrados como opções de tratamento para as crises de hemiplegia causadas por mutações nesse gene. No caso da paciente do relato, talvez o biperideno tenha o mesmo efeito modulador na hiperexcitabilidade neuronal através da bomba de $\mathrm{Na}+/ \mathrm{K}+$, de maneira similar ao observado com a flunarizina e o topiramato10.

Source: The authors (2019).

de minutos a dias ocorrendo em lados do corpo alternados: às vezes, pode iniciar unilateralmente, mas, posteriormente, evoluir para hemiplegia bilateral ou transferir-se para o lado oposto do corpo durante um ataque. Usualmente, a hemiplegia cessa durante o sono e reaparece ao despertar, mas não imediatamente. A deterioração cognitiva não foi associada a episódios de hemiplegia ${ }^{2}$. Alguns autores, inclusive, sugerem que a AHC evolui seguindo três fases distintas com características clínicas relativamente específicas para cada uma dela ${ }^{11}$. (Figura 2)

O início repentino e inesperado de hemiplegia também foi observado em alguns pacientes, mas sempre estando o paciente desperto com hiperventilação ou disfunção autonômica. Fatores desencadeantes podem levar a episódios de hemiplegia, como excitação, estresse, cansaço, trauma, luz forte, calor, frio ou banho ${ }^{12,13}$.
Movimentos involuntários, incluindo discinesia facial, distonia e coreoatetose foram associados às crises de hemiplegia ou ocorreram de forma independente, mesmo na ausência de episódios de hemiplegia, como no caso da paciente do relato que apresentava sinais de distonia de forma crônica².

Nos casos de AHC que se manifestam durante os primeiros dias de vida, distúrbios de movimento ocular (como movimentos involuntários de versão ocular, estrabismo, nistagmo) são, usualmente, os primeiros a serem observados ${ }^{2,10}$. Os movimentos oculares involuntários são caracterizados como desvio intermitente dos olhos, nistagmo e movimento ocular não-conjugado, durando de 1 a 3 minutos. Os movimentos oculares anormais são mais comumente unilaterais e ipsilaterais à hemiplegia ${ }^{14}$.

Sinais prodrômicos antes de fenômenos paroxísticos foram relatados por $41 \%$ dos pacientes. A fase premonitória consiste em uma alteração no 


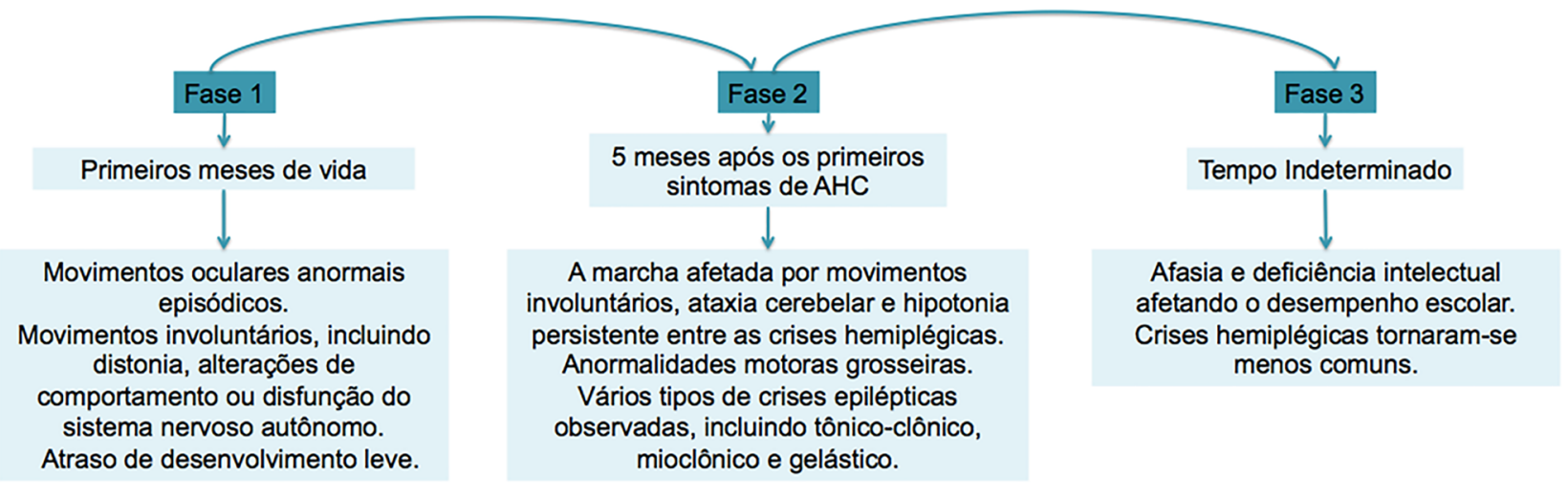

Figura 02: As três fases de evolução dos sintomas em pacientes com AHC11

Fonte: Os autores (2019).

estado mental com gritos, irritabilidade ou alterações comportamentais ${ }^{2}$.

Dores de cabeça podem ocorrer no início de um ataque, mas não depois dele (foram relatados por $58 \%$ das crianças com AHC, embora a enxaqueca com aura tenha sido diagnosticada em 16\%). Movimentos involuntários extrapiramidais (como a coreoatetose) também podem ser uma característica exacerbada pelo quadro de cefaleia ${ }^{2,10}$.

O prognóstico é muito influenciado pela idade de início e especialmente pela ocorrência precoce de crises hemiplégicas na infância. Crianças que apresentaram manifestações de início neonatal geralmente sofrem de grave atraso no desenvolvimento. Crises convulsivas recorrentes podem levar também à deterioração do desenvolvimento psicomotor. Em algumas crianças, a disfunção motora provocada pela doença ocasionou a necessidade de uso de cadeira de rodas, mas outras conseguiram ter uma vida independente na vida adulta. $\grave{A}$ medida que os pacientes envelhecem, as crises hemiplégicas e os movimentos oculares anormais tornam menos comuns e a hipotonia, menos grave ${ }^{2}$.

O tratamento da AHC se baseia no controle dos episódios agudos e em sua profilaxia ${ }^{15}$. Na fase aguda, o foco é na remoção dos gatilhos conhecidos e na facilitação precoce do sono. $\mathrm{O}$ uso do midazolam via oral ou diazepam via retal tem sido defendido por alguns autores por fornecer sedação rápida ${ }^{15}$. Já a profilaxia se baseia em evitar fatores desencadeantes (como privação de sono, por exemplo) e uso de medicamentos a longo prazo para diminuir a frequência das crises. Vários medicamentos têm sido propostos para o tratamento do AHC, mas os bloqueadores dos canais de cálcio são os mais eficazes. O mais comumente usado é a flunarizina, considerada a droga de escolha, com redução da frequência e a gravidade dos ataques, mas não os interrompendo completamente ${ }^{15}$.

Outros tratamentos propostos incluem betabloqueadores, anticonvulsivantes, metissergida, amantadina, aripiprazol e haloperidol ${ }^{3,16}$. As drogas antiepilépticas são efetivas no tratamento apenas das convulsões. O topiramato tem influenciado positivamente a resposta clínica em alguns pacientes com AHC, atenuando os sintomas das crises de $\mathrm{AHC}^{10}$. Recentemente, descreveu-se o uso de adenosina-5'-trifosfato por via oral em pacientes com AHC que foram seguidos por dois anos, evidenciando resultados promissores e bem sucedidos ${ }^{17}$.

Além disso, alguns relatos sugeriram o possível efeito benéfico da dieta cetogênica em pacientes com $A C^{18,19}$. O resultado a longo prazo dos pacientes com AHC é geralmente pouco, devido ao atraso de desenvolvimento associado e à deterioração gradual após ataques mais graves. 
No caso estudado, foi feita a administração do cloridrato de biperideno para redução da distonia e acabou cessando as crises da paciente, além de revelar significativo impacto na evolução da doença. Apesar de não ser a medicação mais indicada neste tratamento, foi observada significativa melhora da qualidade de vida da paciente, inclusive o abandono da cadeira de locomoção.

$O$ biperideno possui ação anticolinérgica muscarínica, exibe ação semelhante ao diltiazem de melhorar a ligação à [3H] nitrendipina, supera a inibição causada pelo tiapamil 2,5 $\mu \mathrm{M}$, aumentando a ligação da [3H] nitrendipina de $10 \%$ a $80 \%$. Apresenta efeitos bifásicos como o diltiazem, causando uma inibição da ligação da [3H] nitrendipina em concentrações mais altas ${ }^{19}$.

O biperideno age também inibindo as contrações dependentes de $\mathrm{Ca} 2$ + do músculo ileal. Pode-se considerar que o biperideno tenha efeito na modulação da hiperexcitabilidade da membrana neuronal, semelhantemente à flunarizina e ao topiramato (Figura 1), o que explicaria a resposta da clínica observada na paciente do relato. Ainda assim, seria importante observar se esse efeito clínico do biperideno ocorre em outros pacientes com AHC cujo controle dos episódios de hemiplegia ainda não esteja sendo feito de forma ideal (mesmo com uso de flunarizina e topiramato).

A mutação observada na paciente já foi previamente descrita na literatura em pacientes apresentando o fenótipo clássico de AHC, com episódios hemiplégicos de difícil controle ${ }^{1,8}$. Em nenhum desses pacientes, contudo, relatou-se uso de biperideno.

Em suma, a AHC é uma grave doença que, juntamente com suas comorbidades associadas, está se tornando cada vez mais reconhecida. Seu diagnóstico e manejo requerem uma equipe multidisciplinar que aborde todos os aspectos dessa doença tão complexa e as necessidades do paciente e da família. A pesquisa clínica direcionada e a colaboração entre os centros que se dedicam a essa doença vêm possibilitando aprofundar a compreensão e melhor manejo terapêutico dessa rara enfermidade ${ }^{3}$.

\section{REFERÊNCIAS}

1. Yang X, Gao H, Zhang J, Xu X, Liu X, Wu X et al. ATP1A3 Mutations and Genotype-Phenotype Correlation of Alternating Hemiplegia of Childhood in Chinese Patients. PLOS ONE 2014; 9: e97274.
2. Gergont A, Kaciński M. Alternating hemiplegia of childhood: New diagnostic options. Neurol Neurochir Pol 2014; 48: 130-135.

3. Masoud M, Prange L, Wuchich J, Hunanyan A, Mikati MA. Diagnosis and Treatment of Alternating Hemiplegia of Childhood. Curr Treat Options Neurol 2017; 19: 8.

4. Ishii $A$, Saito $Y$, Mitsui J, Ishiura $H$, Yoshimura J, Arai $\mathrm{H}$ et al. Identification of ATP1A3 mutations by exome sequencing as the cause of alternating hemiplegia of childhood in Japanese patients. PloS One 2013; 8: e56120.

5. Heinzen EL, Swoboda KJ, Hitomi Y, Gurrieri F, Nicole S, de Vries $B$ et al. De novo mutations in ATP1A3 cause alternating hemiplegia of childhood. Nat Genet 2012; 44: 1030-1034.

6. Schirinzi T, Graziola F, Nicita F, Travaglini L, Stregapede $F$, Valeriani $M$ et al. Childhood Rapid-Onset Ataxia: Expanding the Phenotypic Spectrum of ATP1A3 Mutations. Cerebellum Lond Engl 2018; 17: 489-493.

7. Simmons CQ, Thompson $\mathrm{CH}$, Cawthon BE, Westlake G, Swoboda KJ, Kiskinis E et al. Direct evidence of impaired neuronal $\mathrm{Na} / \mathrm{K}-\mathrm{ATPa}$ e pump function in alternating hemiplegia of childhood. Neurobiol Dis 2018; 115: 29-38.

8. Rosewich H, Sweney MT, DeBrosse S, Ess K, Ozelius L, Andermann $\mathrm{E}$ et al. Research conference summary from the 2014 International Task Force on ATP1A3-Related Disorders. Neurol Genet 2017; 3: e139.

9. Sweney MT, Newcomb TM, Swoboda KJ. The expanding spectrum of neurological phenotypes in children with ATP1A3 mutations, Alternating Hemiplegia of Childhood, Rapid-onset Dystonia-Parkinsonism, CAPOS and beyond. Pediatr Neurol 2015; 52: 56-64.

10. More Than a Decade of Misdiagnosis of Alternating Hemiplegia of Childhood with Catastrophic Outcome. https://www.hindawi.com/journals/ crim/2017/5769837/ (accessed 2 May2019).

11. Mikati MA, Kramer $U$, Zupanc $M L$, Shanahan RJ. Alternating hemiplegia of childhood: clinical manifestations and long-term outcome. Pediatr Neurol 2000; 23: 134-141.

12 Incorpora G, Pavone P, Cocuzza M, Privitera M, Pavone L, Ruggieri M. Neonatal onset of bath-induced alternating hemiplegia of childhood. Eur J Paediatr Neurol EJPN Off J Eur Paediatr Neurol Soc 2010; 14: 192-193.

13. Incorpora $G$, Pavone $P$, Polizzi $A$, Cocuzza M, Privitera $M$, Pavone $L$ et al. An 11-year follow-up study of neonatalonset, bath-induced alternating hemiplegia of childhood in twins. J Child Neurol 2012; 27: 657-662.

14. Heinzen EL, Arzimanoglou A, Brashear A, Clapcote SJ, Gurrieri F, Goldstein DB et al. Distinct neurological disorders with ATP1A3 mutations. Lancet Neurol 2014; 13: $503-514$. 
15. Neville BGR, Ninan $M$. The treatment and management of alternating hemiplegia of childhood. Dev Med Child Neurol 2007; 49: 777-780.

16. Child Neurology: Alternating hemiplegia of childhood | Neurology. https://n.neurology.org/content/74/14/e57 (accessed 14 May2019).

17. Ju J, Hirose S, Shi X-Y, Ishii A, Hu L-Y, Zou L-P. Treatment with Oral ATP decreases alternating hemiplegia of childhood with de novo ATP1A3 Mutation. Orphanet J Rare Dis 2016; 11. doi:10.1186/s13023-016-0438-7.

18. Excellent response to a ketogenic diet in a patient with alternating hemiplegia of childhood. - PubMed - NCBI. https://www.ncbi.nlm.nih.gov/pubmed/24532324 (accessed 3 May2019).

19. Ulate-Campos A, Fons C, Artuch R, Castejón E, Martorell $L$, Ozelius $L$ et al. Alternating hemiplegia of childhood with a de novo mutation in ATP1A3 and changes in SLC2A1 responsive to a ketogenic diet. Pediatr Neurol 2014; 50: 377-379.

20. A unitary mechanism of calcium antagonist drug action. - PubMed - NCBI. https://www.ncbi.nlm.nih.gov/ pubmed/6572372 (accessed 3 May2019). 
Autor Correspondente:

Charles Marques Lourenço

charlesgenetica@gmail.com

Editor:

Prof. Dr Felipe Villela Gomes

Recebido em: 06/02/2020

Aprovado em: 16/11/2020 